Article

\title{
Deacidification of Pistacia chinensis Oil as a Promising Non-Edible Feedstock for Biodiesel Production in China
}

Shenjun Qin ${ }^{1,2, *}$, Yuzhuang Sun ${ }^{1}$, Changlin Shi ${ }^{1}$, Leqin He ${ }^{1}$, Yuan Meng ${ }^{1}$ and Xiaohui Ren ${ }^{1}$

1 Key Laboratory for Resource Exploration Research of Hebei Province, Hebei University of Engineering, Handan, Hebei 056038, China; E-Mails: sun-eee@hotmail.com (Y.S.); chemlab@hebeu.edu.cn (C.S.); heleqin@163.com (L.H.); my198141@163.com (Y.M.); phoenixrxh@163.com (X.R.)

2 State Key Laboratory of Coal Resources and Safe Mining, China University of Mining \& Technology, Beijing 100008, China

* Author to whom correspondence should be addressed; E-Mail: qinsj528@hebeu.edu.cn; Tel.: +86-310-8578759; Fax: +86-310-6025698.

Received: 1 March 2012; in revised form: 29 June 2012 / Accepted: 20 July 2012 /

Published: 31 July 2012

\begin{abstract}
Pistacia chinensis seed oil is proposed as a promising non-edible feedstock for biodiesel production. Different extraction methods were tested and compared to obtain crude oil from the seed of Pistacia chinensis, along with various deacidification measures of refined oil. The biodiesel was produced through catalysis of sodium hydroxide $(\mathrm{NaOH})$ and potassium hydroxide $(\mathrm{KOH})$. The results showed that the acid value of Pistacia chinensis oil was successfully reduced to $0.23 \mathrm{mg} \mathrm{KOH} / \mathrm{g}$ when it was extracted using ethanol. Consequently, the biodiesel product gave a high yield beyond $96.0 \%$. The transesterification catalysed by $\mathrm{KOH}$ was also more complete. Fourier transform infrared (FTIR) spectroscopy was used to monitor the transesterification reaction. Analyses by gas chromatography-mass spectrometry (GC-MS) and gas chromatography with a flame ionisation detector (GC-FID) certified that the Pistacia chinensis biodiesel mainly consisted of $\mathrm{C}_{18}$ fatty acid methyl esters $(81.07 \%)$ with a high percentage of methyl oleate. Furthermore, the measured fuel properties of the biodiesel met the required standards for fuel use. In conclusion, the Pistacia chinensis biodiesel is a qualified and feasible substitute for fossil diesel.
\end{abstract}

Keywords: biodiesel; Pistacia chinensis seed oil; deacidification; transesterification 


\section{Introduction}

Biodiesel is a renewable, green alternative fuel. Compared with fossil fuels, it has many advantages such as environmental friendliness and better efficiency. Many countries throughout the World have attempted to expand the use of biodiesel along with their industrial development. However, the high cost of feedstocks required for biodiesel production, accounting for roughly $60 \%$ to $80 \%$ of the total cost, is a critical restraining factor in its universal commercialisation. [1]. Currently, raw materials for over $95 \%$ of commercially produced biodiesel come from edible oils, such as soybean, rapeseed and palm oil. Large-scale production can be undertaken by the agricultural industry [2], but the excessive use of edible oil to produce biodiesel may cause a series of problems in the World, especially in developing countries including China. The negative impacts of biodiesel production lie in the excessive consumption of crops originally grown to provide food originally and the encroachment on already limited arable lands. These problems lead to the rising prices of edible oils and economic imbalance. Researchers have attempted to search for cheaper non-edible oils as alternative feedstocks for use in biodiesel production. These include Jatropha oil [3,4], Pongamia oil [5], Cornus wisoniana oil [6] and Cerbera oil [7]. Recently, seed oils from Okra (Hibiscus esculentus), Moringa oleifera and Milo (Thespesia populnea), widely distributed in the tropical and subtropical regions, have also been used as suitable feedstocks for biodiesel production [8-10]. However, due to the importance of considering geographical location and climate in different countries in the development of potential biodiesel feedstocks, some oil-producing plants such as Pistacia chinensis are proposed for use in China [11]. This plant can grow in lands that are unsuitable for growing crops, making it suitable for the agricultural conditions in the country [12].

Pistacia chinensis is widely distributed throughout most provinces in China because it is very adaptable; moreover, its seeds have a high oil content of approximatly $40 \%$ [13]. At present, studies on Pistacia chinensis are mainly being reported from China [14] and focus on the biological characteristics and agricultural techniques in propagation and cultivation $[15,16]$, as well as the physical and chemical properties of seed oil [17,18]. There are few reports about using Pistacia chinensis as feedstock to produce biodiesel [19]. However, the high free fatty acid (FFA) content of Pistacia chinensis seed oil may be a major hindrance to the biodiesel production due to the use of dominant industrial basic catalysts [20]. It is well known that the higher FFA content of the feedstock greatly reduces biodiesel yield when using alkaline-catalysis technology. This reduction is attributed to the consumption of catalyst and the difficulties involved in separating and purifying the product [21]. Surprisingly, the acid values of Pistacia chinensis seed oils in China range from $9.7 \mathrm{mg} / \mathrm{g}$ to $79.7 \mathrm{mg} / \mathrm{g}$ due to their different provenances or oil extraction processes [18]. Most of the values, ranging from 10.0 $\mathrm{mg} / \mathrm{g}$ to $20.0 \mathrm{mg} / \mathrm{g}$, are still considerably high for biodiesel production. The content of FFAs in oil should be reduced to less than $0.5 \mathrm{wt} \%$ before an alkaline catalyst could be used for biodiesel production [22].

The first part of this paper focuses on the extraction and deacidification of oil from the seeds of Pistacia chinensis collected from Hebei Province, China The second part focuses on the transesterification of the extracted oil into fatty acid methyl esters. Transesterification reactions were carried out using two homogeneous basic catalysts, namely, sodium hydroxide $(\mathrm{NaOH})$ and potassium hydroxide (KOH). These are the most mature and widely used catalysts in biodiesel production [23]. 
The reactions were monitored using Fourier transform infrared (FTIR) spectroscopy. The biodiesel components were analysed qualitatively and quantitatively by gas chromatography-mass spectrometry (GC-MS) and gas chromatography with aflame ionisation detection (GC-FID). Finally, several physicochemical parameters were tested and compared with the ASTM D 6751 and EU 14214 standards to ensure biodiesel quality. The experimental results show that extraction by solvents, which is first reported when dealing with Pistacia chinensis crude oil, is an effective method in reducing FFA content. The results also show that Pistacia chinensis seed oil is a suitable and promising feedstock for biodiesel production in China.

\section{Experimental}

\subsection{Materials and Apparatus}

Crude oil of Pistacia chinensis was extracted from the seeds, which were purchased in Forestry Co. of Shexian County in Hebei Province, China, and was stored at $4{ }^{\circ} \mathrm{C}$ in the refrigerator. Analytical reagents included methanol (purity $>99.8 \%$ ), sodium hydroxide (purity 99\%), potassium hydroxide (purity 88\%), $n$-hexane (purity 99\%), petroleum ether (boiling point $30 \sim 60{ }^{\circ} \mathrm{C}$ ), anhydrous sodium sulfate (purity 99\%), etc. The analytic apparatus mainly includes Avatar 370 FTIR Spectrometer (Nicolet Co., Madison, WI USA), 6890N/5973N gas chromatography-mass spectrometer, 6890 Gas chromatography (Agilent Co., Wilmington, DE USA), DSY006B Petroleum Pour/Cloud/Solidication/Cold filter plugging tester, SYP1002 Petroleum Flash point tester (Fuli Co., Shanghai, China), and FDR-3601 Octane/Cetane number meter (Fulande Co., Changsha, China).

\subsection{Oil Extraction and Biodiesel Production Procedures}

The Pistacia chinensis seeds were dried at $40{ }^{\circ} \mathrm{C}$ in an oven to remove excess moisture before the extraction process. They were then ground into fine particles. These particles, were extracted with $n$-hexane as the solvent, and the crude seed oil was recovered using a rotary evaporator.

For the homogenous method, the mixture for producing biodiesel was prepared manually by adding $1.0 \mathrm{wt} \%$ sodium or potassium hydroxide-methanol solution to the preheated crude seed oil, whose main components are triacylglycerols. The reactions were carried out in $250 \mathrm{~mL}$ round-bottomed glass flasks placed in a water bath with temperature control. The reaction mixture was vigorously stirred with mechanical stirrer set at $800 \mathrm{rpm}$ stirring rate and refluxed under condensation system for required time. After the reaction, the excessive methanol was evaporated by heating and glycerine in the lower layer was removed; then the upper layer, mainly containing the desired biodiesel product, whose main components are fatty acid methyl esters (FAME), was washed with water. The ester layer after separation was dehydrated with anhydrous sodium sulfate. At last, the refined biodiesel was obtained through filtration. 


\subsection{Analysis}

\subsubsection{Physicochemical Parameters of Crude Oil and Biodiesel}

The density $\left(\mathrm{d}_{4}{ }^{20}\right)$ of crude oil was measured based on GB/T 5526-1985. The acid value (AV) was determined according to $\mathrm{GB} / \mathrm{T}$ 5530-2005. The saponification value $(S V)$ was determined from GB/T 5534-2008. Then the relative molecular weight $(M)$ of crude oil was calculated using the formula [24]:

$$
M=\frac{56.1 \times 3 \times 1000}{S V-A V}
$$

The biodiesel yield was calculated from the biodiesel and oil weights using the following:

$$
\text { Yield } \%=\frac{\text { Weight of biodiesel produced }}{\text { Weight of oil used in reaction }} \times 100 \%
$$

The determined properties of the biodiesel produced included the following: density (ASTM D 5002), kinematic viscosity (ASTM D445), flash point (ASTM D 93), cold filter plugging point (ASTM D 6371), cloud point (ASTM D 2500), pour point (ASTM D 97), ash content (ASTM D 874), acid value (ASTM D 664) and cetane number (ASTM D 613). Triplicate determinations were performed for every experiment, and the data were reported as means \pm standard deviation.

\subsubsection{Biodiesel Chemical Composition}

The FTIR spectra ranging from $400 \mathrm{~cm}^{-1}$ to $4000 \mathrm{~cm}^{-1}$, were collected at 64 scans with a spectral resolution of $4 \mathrm{~cm}^{-1}$. The spectra were analysed using the Omnic 6.1 data processing software. The components and composition of biodiesel were identified qualitatively and calculated quantitatively using GC-MS and GC-FID, respectively. GC-FID analyses were performed on an Agilent 6890 GC equipped with a FID. GC-MS analyses were performed on a same GC coupled to an Agilent 5973 quadrupole mass selective detector (MSD). Separation was achieved on a fused silica capillary column HP-5 (30 $\mathrm{m} \times 0.25 \mathrm{~mm}$ i.d., $0.25 \mu \mathrm{m}$ film thickness, stationary phase of $5 \%$ phenyl and $1 \%$ vinyl dimethyl polysiloxane). The GC operating conditions for both techniques were the same. Temperature increases were initiated from $100{ }^{\circ} \mathrm{C}$ to $280{ }^{\circ} \mathrm{C}$ at a rate of $4{ }^{\circ} \mathrm{C} \mathrm{min}{ }^{-1}$, with isothermal hold at $100{ }^{\circ} \mathrm{C}$ and $280^{\circ} \mathrm{C}$ for $5 \mathrm{~min}$, respectively. Hydrogen and helium were used as carrier gases for GC-FID and GC-MS, respectively. The mass spectrometer was operated in the electron impact mode at $70 \mathrm{eV}$ ionisation energy and scanned from $30 \mathrm{Da}$ to $600 \mathrm{Da}$. Data were acquired and processed using the instrumental software GC and MSD Chemstation.

\section{Results and Discussion}

\subsection{Crude Oil Extraction and Parameter Determination}

Four extraction methods were attempted to obtain oil from Pistacia chinensis seeds. They were carried out under respective optimum conditions according to single factor and orthogonal experiments (detailed data of some preliminary experiments are not provided to preserve the conciseness of this paper). Those processes included the following: (A) leaching at room temperature for $72 \mathrm{~h}$, (B) simple 
reflux extraction at $80{ }^{\circ} \mathrm{C}$ for $5 \mathrm{~h},(\mathrm{C})$ Soxhlet extraction at $80{ }^{\circ} \mathrm{C}$ for $8 \mathrm{~h}$, and (D) ultrasonic extraction for $30 \mathrm{~min}$. The extracted crude oil was weighed, and the average oil content in the seed was calculated (Table 1). The results show that the Soxhlet extraction served as the most effective method in preparing crude oil, with an oil extraction rate reaching to $31.3 \%$. This method is suitable for oil extraction in laboratories, whereas leaching may be used in large-scale industrial preparations because of its very limited energy consumption.

Table 1. Comparison of four extraction methods in preparing Pistacia chinensis seed oil.

\begin{tabular}{lccc}
\hline Extraction method & Seed/g & Oil/g & Yield/\% \\
\hline Leaching & 50 & 13.25 & 26.5 \\
Reflux & 30 & 7.50 & 25.0 \\
Soxhlet & 10 & 3.13 & 31.3 \\
Ultrasonic & 10 & 2.76 & 27.6 \\
\hline
\end{tabular}

The physicochemical parameters of crude oil were determined using the methods stated in the Experimental. The density $\left(\mathrm{d}_{4}{ }^{20}\right)$ was determined to be $0.8751 \mathrm{~g} / \mathrm{mL}$, whereas the average value of acid value $(A V)$ was $33.40 \mathrm{mg} \mathrm{KOH} / \mathrm{g}$, which was much higher than those of most edible oils. The saponification value $(S V)$ was $203.26 \mathrm{mg} \mathrm{KOH} / \mathrm{g}$, and the relative molecular weight $(M)$ was calculated to be 990.8 .

\subsection{Deacidification of Refined Oil}

In order to acquire qualified feedstock for biodiesel production under alkaline catalysis, crude oil has been refined through the degumming process consisting of the following steps: preheating, hydrating, centrifugalising and vacuum dehydrating. Then three methods were compared to check their respective effects on oil deacidification: alkali refining, pre-esterification catalysed by sulfuric acid and extraction by ethanol.

Alkali refining is a traditional method in reducing the acid value of crude oil. Alkali concentration and operating condition are related to the acid value of crude oil (Table 2) [24]. The stoichiometric alkali dosage is calculated using the following formula. Excessive alkali used in practice typically range from $0.05 \%$ to $0.25 \%$ :

$$
G_{\mathrm{NaOH}}=\mathrm{G}_{\mathrm{oil}} \times \mathrm{AV} \times \frac{M_{\mathrm{NaOH}}}{M_{\mathrm{KOH}}} \times \frac{1}{1000}
$$

Table 2. Alkali concentration and the operating temperature according to acid value of crude oil.

\begin{tabular}{cccc}
\hline \multirow{2}{*}{ Acid value of crude oil } & \multirow{2}{*}{ Alkali concentration/ ${ }^{\circ}$ Bé } & \multicolumn{2}{c}{ Operating temperature $/{ }^{\circ} \mathbf{C}$} \\
\cline { 3 - 4 } & & Start & End \\
\hline$<5$ & $4 \sim 6$ & $75 \sim 80$ & $90 \sim 95$ \\
$5 \sim 7$ & $12 \sim 14$ & $50 \sim 55$ & $60 \sim 65$ \\
$7 \sim 9$ & $16 \sim 24$ & $25 \sim 30$ & $45 \sim 50$ \\
$>9$ & $>24$ & $20 \sim 30$ & $20 \sim 30$ \\
\hline
\end{tabular}


Unexpectedly, the result showed that alkali refining was not a satisfactory method in dealing with Pistacia chinensis crude oil with so much high FFA content. Specifically, the acid value decreased to $2.10 \mathrm{mg} \mathrm{KOH} / \mathrm{g}$ under the the following optimum conditions: $30.0 \mathrm{~g}$ crude oil, $0.2 \%$ extra sodium hydroxide $0.77 \mathrm{~g}$, temperature increase from $20^{\circ} \mathrm{C}$ to $30{ }^{\circ} \mathrm{C}$, and stirring rate of $30 \mathrm{r} / \mathrm{min}$.

Pre-esterification can be also regarded as the first step performed in two-step biodiesel production using oil with high FFA content as feedstock [25]. With methanol, the high content FFA can be transformed into fatty acid methyl esters (FAMEs) through the catalysis initiated by sulfuric acid. In the present study, the experiment was carried out under optimum conditions, i.e., the molar ratio of methanol to oil was 1 to 10 , the amount of the catalyst addition was $3.0 \mathrm{wt} \%$, reaction time was $4 \mathrm{~h}$, and the temperature was controlled at $60{ }^{\circ} \mathrm{C}$. However, we found that the deacidification result of the acid value $2.24 \mathrm{mg} \mathrm{KOH} / \mathrm{g}$ was not ideal. Thus, the two-step biodiesel production method commonly used in feedstocks with high acid value may not be suitable in processing Pistacia chinensis seed oil.

Finally, given the solubility of FFAs in polar solvents (e.g., isopropyl alcohol, ethanol, and methyl alcohol), an extraction method with these solvents was attempted to reduce FFA content. This method is seldom reported when processing crude oil for biodiesel production. Based on our experimental data, this extraction method showed an excellent deacidification effect, and had shorter operating time and lower cost compared with two former methods. To obtain the best experimental conditions, three aspects that influence the deacidification were studied: volume ratio of oil to ethanol, extraction temperature, number of repetitions (Figure 1).

Figure 1. Single factor experiments of Pistacia chinensis oil deacidification with ethanol.

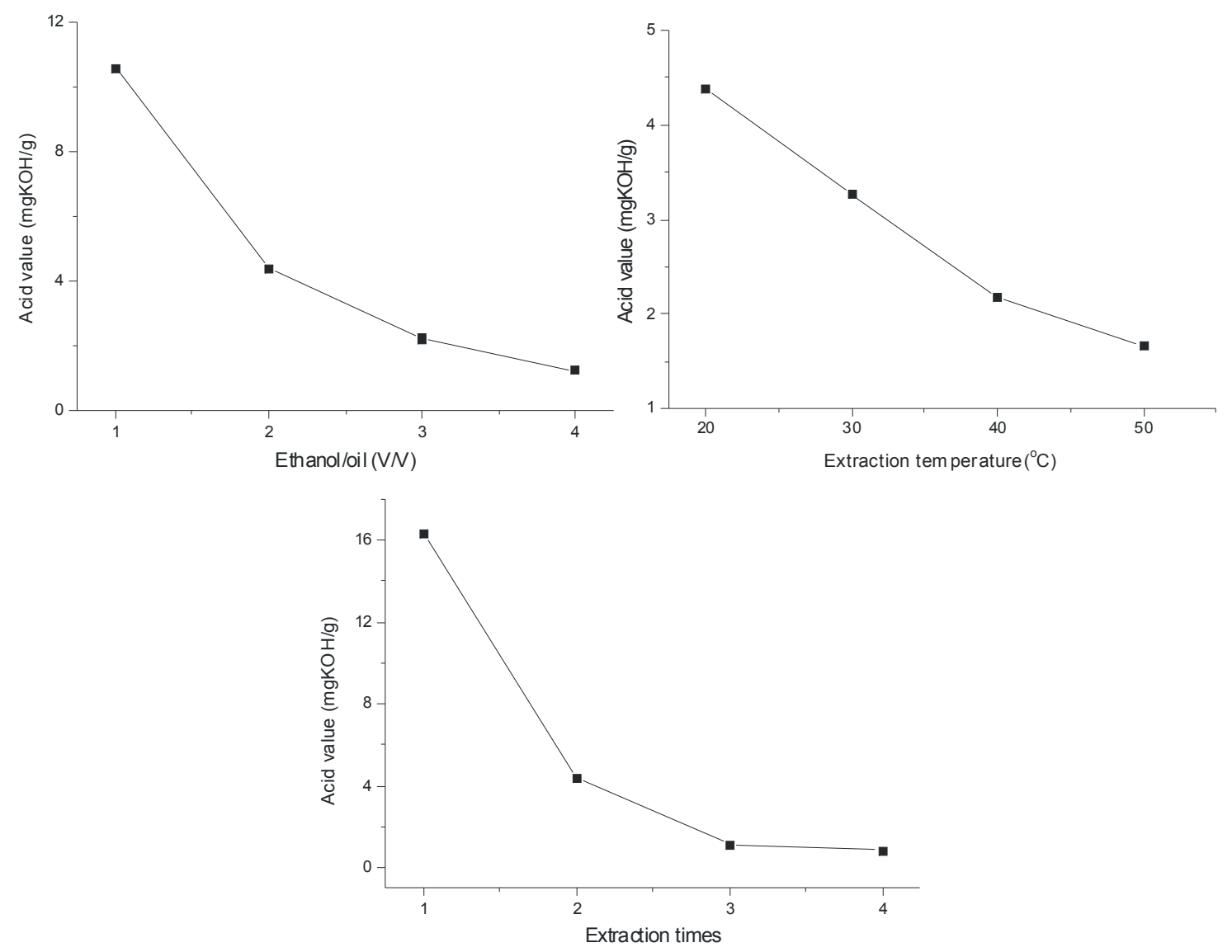


An orthogonal experiment featuring the three levels and the four factors (the fourth was a blank factor added) was designed (Table 3a,b).

Table 3. (a) L $\mathrm{L}_{9}\left(3^{4}\right)$ orthogonal experimental program of Pistacia chinensis oil deacidification by ethanol; (b) Orthogonal experimental results of Pistacia chinensis oil deacidification by ethanol.

(a)

\begin{tabular}{lcccc}
\hline Levels & $\begin{array}{c}\text { The volume ratio of } \\
\text { oil to ethanol (A) }\end{array}$ & $\begin{array}{c}\text { Extraction } \\
\text { temperature (B) }\end{array}$ & $\begin{array}{c}\text { Extraction } \\
\text { times (C) }\end{array}$ & Blank \\
\hline 1 & $1: 1$ & $20{ }^{\circ} \mathrm{C}$ & 1 & 1 \\
2 & $1: 2$ & $30{ }^{\circ} \mathrm{C}$ & 2 & 2 \\
3 & $1: 3$ & $40{ }^{\circ} \mathrm{C}$ & 3 & 3 \\
\hline
\end{tabular}

(b)

\begin{tabular}{|c|c|c|c|c|c|}
\hline Test No. & $\begin{array}{c}\text { The volume ratio } \\
\text { of oil to ethanol } \\
\text { (A) } \\
\end{array}$ & $\begin{array}{c}\text { Extraction } \\
\text { temperature }\left({ }^{\circ} \mathrm{C}\right)(\mathrm{B})\end{array}$ & $\begin{array}{l}\text { Extraction } \\
\text { times }(C)\end{array}$ & Blank & $\begin{array}{l}\text { Acid value } \\
\text { (mg KOH/g) }\end{array}$ \\
\hline 1 & $1: 1$ & 20 & 1 & 1 & 22.51 \\
\hline 2 & $1: 1$ & 30 & 2 & 2 & 9.87 \\
\hline 3 & $1: 1$ & 40 & 3 & 3 & 4.37 \\
\hline 4 & $1: 2$ & 20 & 2 & 3 & 4.38 \\
\hline 5 & $1: 2$ & 30 & 3 & 1 & 0.55 \\
\hline 6 & $1: 2$ & 40 & 1 & 2 & 13.62 \\
\hline 7 & $1: 3$ & 20 & 3 & 2 & 1.13 \\
\hline 8 & $1: 3$ & 30 & 1 & 3 & 9.03 \\
\hline 9 & $1: 3$ & 40 & 2 & 1 & 1.65 \\
\hline $\mathrm{K}_{1}$ & 36.75 & 28.02 & 45.16 & 24.71 & \\
\hline $\mathrm{K}_{2}$ & 18.55 & 19.45 & 15.90 & 24.62 & \\
\hline $\mathrm{K}_{3}$ & 11.81 & 19.64 & 6.05 & 17.78 & \\
\hline$\overline{\mathrm{K}}_{13}$ & 12.250 & 9.340 & 15.053 & 8.237 & \\
\hline$\overline{\mathrm{K}}_{23}$ & 6.183 & 6.483 & 5.300 & 8.207 & \\
\hline$\overline{\mathrm{K}}_{33}$ & 3.937 & 6.547 & 2.017 & 5.927 & \\
\hline $\mathrm{R}$ & 24.94 & 8.57 & 39.11 & 6.93 & \\
\hline $\begin{array}{l}\text { Priority } \\
\text { factors }\end{array}$ & \multicolumn{5}{|c|}{$\mathrm{C}>\mathrm{A}>\mathrm{B}$} \\
\hline $\begin{array}{l}\text { Optimum } \\
\text { solution }\end{array}$ & \multicolumn{5}{|c|}{$\mathrm{K}_{3 \mathrm{~A}}<\mathrm{K}_{2 \mathrm{~A}}<\mathrm{K}_{1 \mathrm{~A}} \mathrm{~K}_{2 \mathrm{~B}}<\mathrm{K}_{3 \mathrm{~B}}<\mathrm{K}_{1 \mathrm{~B}} \mathrm{~K}_{3 \mathrm{C}}<\mathrm{K}_{2 \mathrm{C}}<\mathrm{K}_{1 \mathrm{C}}$} \\
\hline & \multicolumn{5}{|c|}{$\mathrm{A}_{3} \mathrm{~B}_{2} \mathrm{C}_{3}$} \\
\hline
\end{tabular}

The experimental results revealed that the optimum parameter combination of Pistacia chinensis oil deacidification was $\mathrm{A}_{3} \mathrm{~B}_{2} \mathrm{C}_{3}$; this meant that the volume ratio of oil to ethanol was $1: 3$, extraction temperature was $30{ }^{\circ} \mathrm{C}$, and the number of repetitions was 3 . After performing three confirmatory experiments under optimum conditions, we also found that the average acid value was reduced to $0.23 \pm 0.02 \mathrm{mg} \mathrm{KOH} / \mathrm{g}$. This value was much lower than that for alkali refining and pre-esterification under optimum conditions. 


\subsection{Biodiesel Production and Analysis}

Pistacia chinensis biodiesel was produced under homogeneous basic catalysis by $\mathrm{NaOH}$ and $\mathrm{KOH}$. The optimum reaction conditions were as follows: 6:1 molar ratio of methanol to oil, addition of $1.0 \mathrm{wt} \%$ catalyst, $60 \mathrm{~min}$ reaction time, and $60{ }^{\circ} \mathrm{C}$ reaction temperature. In a former study conducted by the researchers using the same experimental conditions [20], the average biodiesel yield from the seed oil of Pistacia chinensis plant from an identical location was only $67.5 \%$. The reason for the lower biodiesel yield in that study was the corresponding lower quality of the oil. Furthermore, the acid value of refined oil was reduced to $2.10 \mathrm{mg} \mathrm{KOH} / \mathrm{g}$ through the process of degumming and alkali refining. When using the homogeneous alkaline catalysis, the higher FFA content of the feedstock generally reduce biodiesel yield due to the consumption of catalyst and the difficulties involved in separating and purifying of the product [21]. In contrast, all parallel experiments yielded more than $96.0 \%$ biodiesel, because the acid value of $0.23 \mathrm{mg} \mathrm{KOH} / \mathrm{g}$ was converted into an FFA content of approximately $0.13 \mathrm{wt} \%$ after ethanol deacidification. This value is much less than $0.5 \mathrm{wt} \%$, which is the upper limit in biodiesel production under basic catalysis.

Furthermore, it can be inferred that transesterification was thoroughly catalyzed by both $\mathrm{NaOH}$ and $\mathrm{KOH}$. However, the biodiesel yield $(97.06 \pm 0.14)$ under $\mathrm{KOH}$ catalysis was slightly higher than that of $\mathrm{NaOH}$ catalysis $(96.62 \pm 0.30)$. From the chemometrics aspect, $1.4 \mathrm{wt} \% \mathrm{KOH}$ offered an equivalent $\mathrm{OH}^{-}$of $1 \mathrm{wt} \% \mathrm{NaOH}$, Meanwhile only $1 \mathrm{wt} \% \mathrm{KOH}$ can give better catalysis effect than $1 \mathrm{wt} \% \mathrm{NaOH}$. This may be caused by the stronger alkalinity of $\mathrm{KOH}$, which promoted the reaction more completely. Consequently, $\mathrm{KOH}$ was identified as a better catalyst candidate than $\mathrm{NaOH}$ in terms of chemical behaviour. This finding corresponds with the results of similar studies on transesterification reactions [26,27]. In addition, the use of $\mathrm{KOH}$ is more economically feasible because at the end of the reaction, the mixture can be neutralised with phosphoric acid to produce potassium phosphate-a type of fertiliser [28].

\subsection{Biodiesel Analysis}

The biodiesel produced from Pistacia chinensis was characterised using FTIR spectroscopy. FTIR spectra show characteristic FAME bands (Figure 2). In the functional group - $\mathrm{CO}-\mathrm{O}-\mathrm{CH}_{3}$ of the FAME, which was generated during the transesterification, $2854 \mathrm{~cm}^{-1}$ and $2925 \mathrm{~cm}^{-1}$ were attributed to the stretching and asymmetric stretching vibrations of $-\mathrm{CH}_{3} ; 1436 \mathrm{~cm}^{-1}$ corresponded to the asymmetric bending vibration of $-\mathrm{CH}_{3} ; 1196 \mathrm{~cm}^{-1}$ was due to the stretching vibration from $\mathrm{O}-\mathrm{CH}_{3}$; and $1743 \mathrm{~cm}^{-1}$ was assigned to the vibration of $-\mathrm{C}=\mathrm{O}$. These results reflect the conversion of triacylglycerols into methyl esters [29].

The main components of biodiesel from Pistacia chinensis were analysed qualitatively and quantitatively through GC-MS and GC-FID (Figure 3). The components included methyl palmitate, methyl linoleate, methyl oleate and methyl stearate (Table 4). The minor components included other kinds of FAMEs and traces of monoacylglycerols. The proposed chemical structure of biodiesel is $\mathrm{C}_{19} \mathrm{H}_{36} \mathrm{O}_{2}$ [24]. This suggestion means that $\mathrm{C}_{18}$ FAMEs -including high percentage of methyl oleate-should be dominant in the biodiesel. Therefore, this Pistacia chinensis biodiesel with $81.07 \% \mathrm{C}_{18}$ FAMEs is a chemical qualified product as biofuel. 
Figure 2. FTIR spectrum of Pistacia chinensis biodiesel.

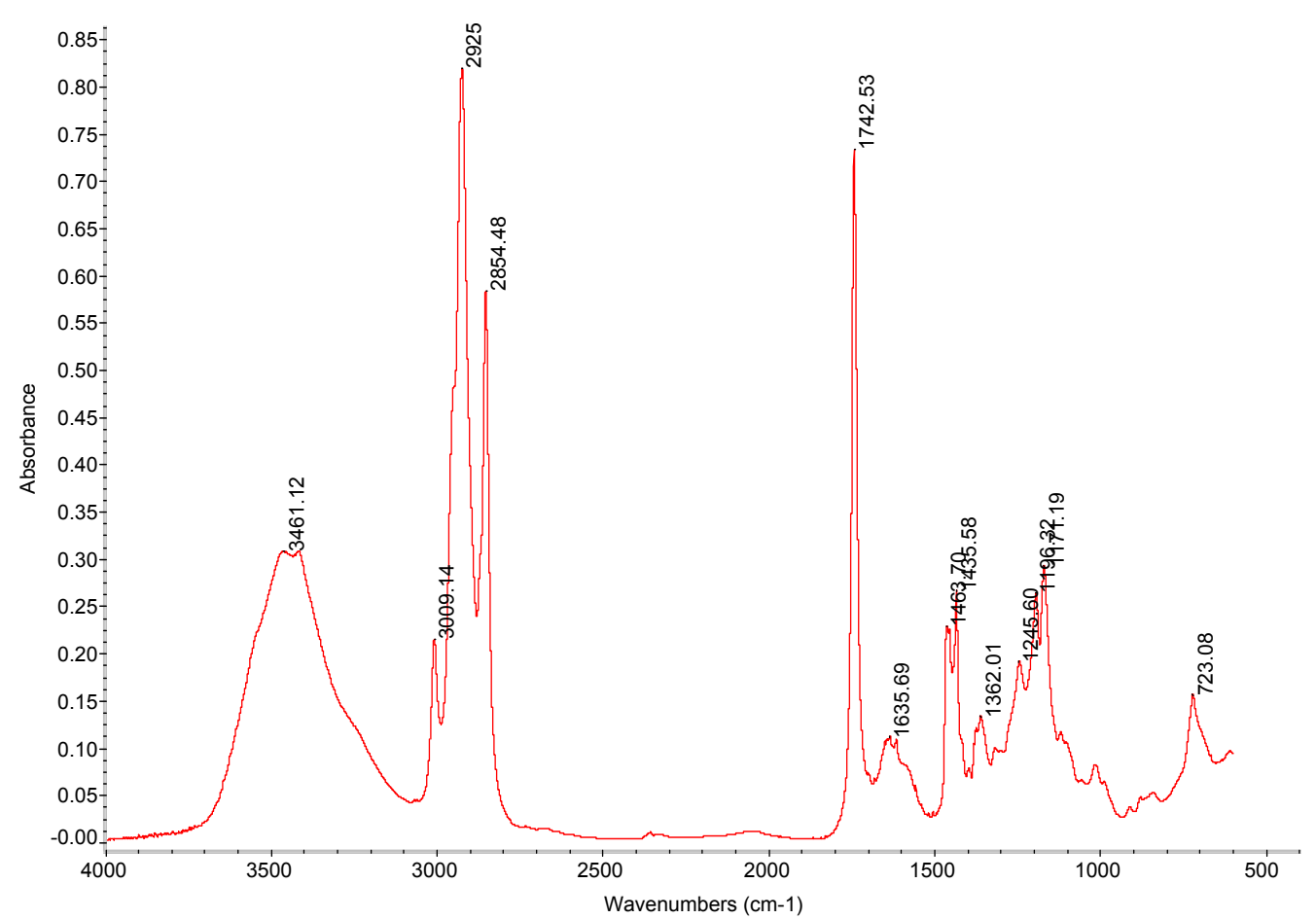

Figure 3. GC-MS (TIC) traces of Pistacia chinensis biodiesel.

Abundance

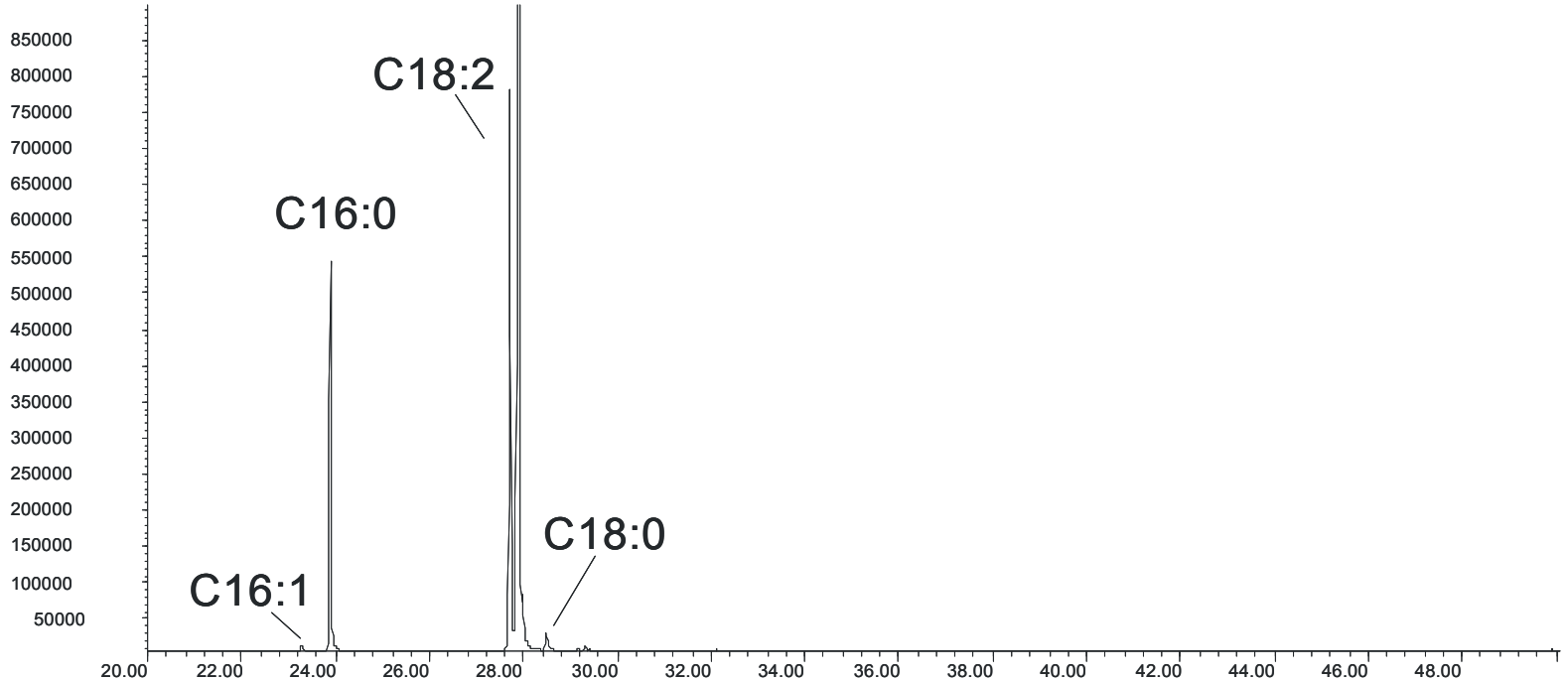

Table 4. Composition (\%) of biodiesel of Pistacia Chinensis.

\begin{tabular}{lcccc}
\hline Components & Methyl palmitate & Methyl linoleate & Methyl oleate & Methyl stearate \\
\hline Formula & $\mathrm{C} 16: 0$ & $\mathrm{C} 18: 2$ & $\mathrm{C} 18: 1$ & $\mathrm{C} 18: 0$ \\
Composition (\%) & $18.93 \pm 0.28$ & $27.42 \pm 0.40$ & $52.32 \pm 1.15$ & $1.33 \pm 0.16$ \\
\hline
\end{tabular}

With the aim to test whether or not the Pistacia chinensis biodiesel meets the required standards for fuel use. In line with this, several key fuel properties of the refined product have been identified. These properties are given in Table 5. The cetane number reflects the ignition quality of diesel fuel, which 
strongly affects engine performance in terms of combustion and exhaust emissions among others. The greater the cetane number, the more ignitable the fuel is [8]. The cetane number (52.2) of Pistacia chinensis biodiesel meets the minimum requirements mandated in both the ASTM D6751 and EN 14214 biodiesel standards. The kinematic viscosity affects the atomisation when a fuel is injected into the combustion chamber; this process may lead to the formation of soot and engine deposits [8]. The kinematic viscosity values of methyl oleate, methyl linoleate, and methyl palmitate are 4.51, 3.65 and $4.38 \mathrm{~mm}^{2} \mathrm{~s}^{-1}$ at $40{ }^{\circ} \mathrm{C}$, respectively [30]. The kinematic viscosity $\left(5.24 \mathrm{~mm}^{2} \mathrm{~s}^{-1}\right)$ of Pistacia chinensis biodiesel falls within the specified range in ASTM D6751. However, the value is slightly higher than that stated in the EN 14214 biodiesel standards, which may be due to the high percentage of methyl oleate. Although no limits are specified in both standards, the relatively low values of cloud point $\left(1^{\circ} \mathrm{C}\right)$, pour point $\left(-2{ }^{\circ} \mathrm{C}\right)$, and cold filter plugging point $\left(0^{\circ} \mathrm{C}\right)$ of the biodiesel produced in the present study, compared with those of biodiesel from other non-edible feedstocks [8-10], show that Pistacia chinensis biodiesel has good cold flow properties. The higher flash point value of the product $\left(166{ }^{\circ} \mathrm{C}\right)$ also reduces the risk of fires, which is one of the superior properties of biodiesel. Other fuel properties of this Pistacia chinensis biodiesel include density $\left(887 \mathrm{~kg} \mathrm{~m}^{-3}\right)$, ash content $(0.013 \%)$ and acid value (0.35 $\left.\mathrm{mg} \mathrm{KOH} \mathrm{g}^{-1}\right)$, These values are also comparable with those of diesel according to ASTM D6751 and EN 14214 standards (Table 5).

Table 5. Property comparison of Pistacia chinensis biodiesel with ASTM D6751 and EN 14214 standards.

\begin{tabular}{lccc}
\hline Fuel property & Biodiesel & ASTM D6751 & EN 14214 \\
\hline Density $\left(15^{\circ} \mathrm{C}\right), \mathrm{kg} \mathrm{m}^{-3}$ & $887 \pm 9.6^{*}$ & - & $860-900$ \\
Kinematic viscosity $\left(\mathrm{mm}^{2} \mathrm{~s}^{-1} ; 40{ }^{\circ} \mathrm{C}\right)$ & $5.24 \pm 0.05$ & $1.9-6.0$ & $3.5-5.0$ \\
Flash point $\left({ }^{\circ} \mathrm{C}\right)$ & $166 \pm 2.0$ & $130 \mathrm{~min}$ & $120 \mathrm{~min}$ \\
Cloud point $\left({ }^{\circ} \mathrm{C}\right)$ & $1.00 \pm 0.12$ & Report & - \\
Pour point $\left({ }^{\circ} \mathrm{C}\right)$ & $-2.00 \pm 0.15$ & - & - \\
Cold filter plugging point $\left({ }^{\circ} \mathrm{C}\right)$ & $0.00 \pm 0.10$ & - & - \\
Ash content $(\%)$ & $0.013 \pm 0.001$ & $0.02 \mathrm{max}$ & $0.02 \mathrm{max}$ \\
Acid value $\left(\mathrm{mg} \mathrm{KOH} \mathrm{g}^{-1}\right)$ & $0.35 \pm 0.03$ & $0.50 \mathrm{max}$ & $0.50 \mathrm{max}$ \\
Cetane number & $52.2 \pm 1.30$ & $47 \mathrm{~min}$ & $51 \mathrm{~min}$ \\
\hline
\end{tabular}

* Values are mean $\pm \mathrm{SD}$ of triplicate determination.

\section{Conclusions}

The Pistacia chinensis oil-bearing plant is widely distributed in China, and represents an ideal and promising feedstock for biodiesel production. However, the high free fatty acids content of its crude oil may be a handicap in achieving widespread industrial applications. After comparing three deacidification methods, we find that extraction with ethanol is the most effective. In this method, the acid value of refined oil was successfully reduced to $0.23 \mathrm{mg} \mathrm{KOH}^{-1}$. Using this qualified oil, biodiesel with high yield $(>96.0 \%)$ has been produced under catalysis by potassium and sodium hydroxides. $\mathrm{KOH}$ demonstrated better catalysing effect than $\mathrm{NaOH}$. Finally, the characteristics of the FTIR spectra indicated the complete transesterification. The analyses of GC-MS and GC-FID likewise verified the chemical structural feasibility of Pistacia chinensis biodiesel as a substitute for fossil diesel, Likewise, several major fuel properties of the biodiesel have been measured, and these met the required standards for fuel use. 


\section{Acknowledgments}

We acknowledge the financial support from the National Natural Science Foundation of China (No. 41102095), the Science Foundation of Hebei province (No. D2012402012), the Science and Technology Foundation for Outstanding Young Scholars of Universities of Hebei Province (No. Y201103), and the Foundation of State Key Laboratory for Coal Resources and Safe Mining, China University of Mining \& Technology (No. SKLCRSM10KFB07). We also thank Meng Li from Handan Bureau of Quality and Technical Supervision for his excellent technical assistance on the determinations of fuel properties of the biodiesel produced.

\section{References}

1. Leung, D.Y.C.; Xuan, W.; Leung, M.K.H. A review on biodiesel production using catalyzed transesterification. Appl. Energy 2010, 87, 1083-1095.

2. Gui, M.M.; Lee, K.T.; Bhatia, S. Feasibility of edible oil vs. non-edible oil vs. waste edible oil as biodiesel feedstock. Energy 2008, 33, 1646-1653.

3. Vyas, A.P.; Subrahmanyam, N.; Patel, P.A. Production of biodiesel through transesterification of Jatropha oil using $\mathrm{KNO}_{3} / \mathrm{Al}_{2} \mathrm{O}_{3}$ solid catalyst. Fuel 2009, 88, 625-628.

4. De Oliveira, J.S.; Leite, P.M.; De Souza, L.B.; Mello, V.M.; Silva, E.C.; Rubim, J.C.; Meneghetti, S.M.P.; Suarez, P.A.Z. Characteristics and composition of Jatropha gossypiifolia and Jatropha curcas L. oils and application for biodiesel production. Biomass Bioenergy 2009, 33, 449-453.

5. Meher, L.C.; Dharmagadda, V.S.S.; Naik, S.N. Optimization of alkali-catalyzed transesterification of Pongamia pinnata oil for production of biodiesel. Bioresour. Technol. 2006, 97, 1392-1397.

6. Zhang, A.H.; Zhang, Y.J.; Xiao, Z.H.; Li, P.W.; Li, C.Z. Synthesis of biodiesel catalyzed by 1-(4-sulfonic acid) butyl-pyridinium hydrosulfate ionic liquid. Petrochem. Technol. 2009, 38, $47-51$.

7. Kansedo, J.; Lee, K.T.; Bhatia, S. Cerbera odollam (sea mango) oil as a promising non-edible feedstock for biodiesel production. Fuel 2009, 88, 1148-1150.

8. Anwar, F.; Rashid, U.; Ashraf, M.; Nadeem, M. Okra (Hibiscus esculentus) seed oil for biodiesel production. Appl. Energy 2010, 87, 779-785.

9. Rashid, U.; Anwar, F.; Ashraf, M.; Saleem, M.; Yusup, S. Application of response surface methodology for optimizing transesterification of Moringa oleifera oil: Biodiesel production. Energ. Convers. Manag. 2011, 52, 3034-3042.

10. Rashid, U.; Anwar, F.; Knothe, G. Biodiesel from Milo (Thespesia populnea L.) seed oil. Biomass Bioenergy 2011, 35, 4034-4039.

11. Shao, H.B.; Chu, L.Y. Resource evaluation of typical energy plants and possible functional zone planning in China. Biomass Bioenergy 2008, 32, 283-288.

12. Min, E.Z.; Tang, Z.; Du, Z.X.; Wu, W. Perspective of biodiesel industry in China. Eng. Sci. 2005, $7,1-4$.

13. Hou, X.C.; Mou, H.X.; Yang, S.C.; Xing, Y.Z.; Jing, J. Research progress in woody energy plant Pistacia chinensis. J. Anhui Agri. Sci. 2007, 35, 3524-3525. 
14. Li, H.L.; Zhang, Z.X.; Lin, S.Z.; Li, X.X. Research advances in the study of Pistacia chinensis Bunge, a superior tree species for biomass energy. For. Study China 2007, 9, 164-168.

15. Niu, Z.T.; Li, T.; Jian, G.Z.; Zhang, Y.J. Resource survey, cultivation techniques and multipurpose utilization of Pistacia chinensis bunge. Nonwood For. Res. 2005, 23, 68-71.

16. Qian, X.X.; Zhang, W.M.; Gu, G.P.; Zhang, G.L. The ultilization and cultivation of fuel plant Pistacia chinensis. Chin. Wild Plant Res. 2007, 26, 14-16.

17. Hu, X.H.; Ni, W.S.; Zhou, Y.; Chen, Y.; Li, Q.; Deng, L. Analytical study on the physical and chemical index and the composition of FA of Pistacia chinensis bge seed oil. J. Wuhan Polytech. Univ. 2007, 26, 8-9.

18. Chen, L.S.; Peng, F.R.; Liang, Y.W.; Zhang, C.X. Difference analysis of seed morphological characters and oil quality of Pistacia chinensis from different provenances. J. Plant Res. Env. 2009, 18, 16-21.

19. Yu, X.H.; Wen, Z.; Li, H.L.; Tu, S.T.; Yan, J.Y. Transesterification of Pistacia chinensis oil for biodiesel catalyzed by $\mathrm{CaO}-\mathrm{CeO}_{2}$ mixed oxides. Fuel 2011, 90, 1868-1874.

20. Qin, S.J.; Sun, Y.Z.; Meng, X.C.; Zhang, S.X. Production and analysis of biodiesel from non-edible seed oil of Pistacia chinensis. Energy Explor. Exploit. 2010, 28, 37-46.

21. Marchetti, J.M.; Miguel, V.U.; Errazu, A.F. Heterogeneous esterification of oil with high amount of free fatty acids. Fuel 2007, 86, 906-910.

22. Van Gerpen, J. Biodiesel processing and production. Fuel Process. Technol. 2005, 86, 1097-1107.

23. Kucek, K.T.; Cesar-Oliveira, M.A.F.; Wilhelm, H.M.; Ramos, L.P. Ethanolysis of refined soybean oil assisted by sodium and potassium hydroxides. J. Am. Oil Chem. Soc. 2007, 84, 385-392.

24. Li, C.Z.; Jiang, L.J.; Cheng, S.Q. Green Energy Resources-Biodiesel; Chemical Industrial Press: Beijing, China, 2005.

25. Wang, Y.; Ou, S.Y.; Liu, P.Z.; Zhang, Z.S. Preparation of biodiesel from waste cooking oil via two-step catalyzed process. Energy Convers. Manag. 2007, 48, 184-188.

26. Dorado, M.P.; Ballesteros, E.; Mittelbach, M.; Lopez, F.J. Kinetic parameters affecting the alkali-catalyzed transesterification process of used olive oil. Energy Fuels 2004, 18, 1457-1462.

27. Encinar, J.M.; Gonzalez, J.F.; Rodriguez-Reinares, A. Ethanolysis of used frying oil. Biodiesel preparation and characterization. Fuel Process. Technol. 2007, 88, 513-522.

28. Monteiro, M.R.; Ambrozin, A.R.P.; Liao, L.M.; Ferreira, A.G. Critical review on analytical methods for biodiesel characterization. Talanta 2008, 77, 593-605.

29. Siatis, N.G.; Kimbaris, A.C.; Pappas, C.S.; Tarantilis, P.A.; Polissiou, M.G. Improvement of biodiesel production based on the application of ultrasound: Monitoring of the procedure by FTIR spectroscopy. J. Am. Oil Chem. Soc. 2006, 83, 53-57.

30. Knothe, G.; Steidley, K.R. Kinematic viscosity of biodiesel fuel components and related compounds: Influence of compound structure and comparison to petrodiesel fuel components. Fuel 2005, 84, 1059-1065.

(C) 2012 by the authors; licensee MDPI, Basel, Switzerland. This article is an open access article distributed under the terms and conditions of the Creative Commons Attribution license (http://creativecommons.org/licenses/by/3.0/). 